\title{
Optimising Repeated Exposure: Determining Optimal Exposure Frequency for Introducing a Novel Vegetable among Children
}

\author{
Klelia Karagiannaki ${ }^{1}{ }^{(D}$, Christian Ritz $^{2}{ }^{\mathbb{D}}$, Louise Grønhøj Hørbye Jensen ${ }^{1}$, Ellen Hyldgaard Tørsleff ${ }^{1}$, \\ Per Møller ${ }^{1,+} \mathbb{D}$, Helene Hausner ${ }^{1, \ddagger}$ and Annemarie Olsen ${ }^{1, * \mathbb{D}}$ \\ 1 Section for Food Design and Consumer Behaviour, Department of Food Science, Faculty of Science, \\ University of Copenhagen, Rolighedsvej 26, 1958 Frederiksberg C, Denmark; \\ klelia.karagiannaki@outlook.com (K.K.); lghj@dtu.dk (L.G.H.J.); ellen_toersleff@hotmail.com (E.H.T.); \\ p2moller@gmail.com (P.M.); helene.hausner@gmail.com (H.H.) \\ 2 Department of Nutrition and Exercise Science, Faculty of Science, University of Copenhagen, Rolighedsvej 25, \\ 1958 Frederiksberg C, Denmark; ritz@nexs.ku.dk \\ * Correspondence: ano@food.ku.dk; Tel.: +45-35-33-1018 \\ † Current addres: Per Møller Consulting, Langemosevej 17, 2880 Bagsværd, Denmark. \\ $\ddagger$ Current addres: Helene Hausner, ALK Abelló, Bøge Alle 6, 2970 Hørsholm, Denmark.
}

Citation: Karagiannaki, K.; Ritz, C.; Jensen, L.G.H.; Tørsleff, E.H.; Møller, P.; Hausner, H.; Olsen, A. Optimising Repeated Exposure: Determining Optimal Exposure Frequency for Introducing a Novel Vegetable among Children. Foods 2021, 10, 913. https:// doi.org/10.3390/foods10050913

Academic Editor: Monica Laureati

Received: 5 March 2021

Accepted: 13 April 2021

Published: 21 April 2021

Publisher's Note: MDPI stays neutral with regard to jurisdictional claims in published maps and institutional affiliations.

Copyright: (c) 2021 by the authors. Licensee MDPI, Basel, Switzerland. This article is an open access article distributed under the terms and conditions of the Creative Commons Attribution (CC BY) license (https:// creativecommons.org/licenses/by/ $4.0 /)$.
Abstract: Fruit and vegetables are important components of a healthy diet, but unfortunately many children are not consuming enough to meet the recommendations. Therefore, it is crucial to develop strategies towards increasing the acceptance of this food group. This study aims to investigate the effect of different repeated exposure frequencies on fruit and vegetable acceptance using a novel vegetable, daikon, among 3-6-year-old children. One hundred and fifty-nine children participated in this study. Eight kindergarten teams were assigned to one of the following groups: Three different intervention groups with varying exposure frequencies, but all receiving seven exposures: Twice a week $(n=47)$, once a week $(n=32)$ and once every second week $(n=30)$, and a control group $(n=50)$. Liking and familiarity of daikon and other vegetables (cucumber, celery, celeriac, broccoli, cauliflower and beetroot) were assessed at baseline, post-intervention and two follow up sessions ( 3 and 6 months) to test for potential generalisation effects and observe the longevity of the obtained effects. Intake of daikon was measured at all exposures and test sessions. Results showed significant increases $(p \leq 0.05)$ in liking and intake of daikon for all three frequencies and the control group. Over the exposures, intake of daikon increased until the 4th exposure for all the groups, where a plateau was reached. No systematic generalisation effects were found. Repeated exposure was a successful approach to increase liking and intake of a novel vegetable with all exposure frequencies to be effective, and no particular exposure frequency can be recommended. Even the few exposures the control group received were found to be sufficient to improve intake and liking over 6 months $(p \leq 0.05)$, indicating that exposures to low quantities of an unfamiliar vegetable may be sufficient.

Keywords: repeated exposure; mere exposure; children; vegetables; taste; preferences; intervention

\section{Introduction}

The prevention of many chronic diseases has been shown to be reinforced by the consumption of a diet high in fruit and vegetables [1-3] as a result of their low energy but high fibre and important micronutrient content $[1,4,5]$. The recommended intake of fruit and vegetables for 4-10-year-old children in Denmark is 300-500 g per day, with half of the consumed quantity to consist of vegetables [6,7]. Pedersen et al. [5] showed that the consumption of vegetables of Danish children is lower than the recommended amount, a fact that is complemented by another survey of the same period which found that, even if the intake of vegetables had been improved, it was still under that of the guidelines [8]. An interesting finding was that vegetables were mostly consumed at lunch and dinner [9] 
compared to breakfast and in between meals, which were mostly high in sugar and fat [10]. The consumption of those high-calorie snacks instead of the rich in fibre and antioxidants fruits and vegetables, is one of the key risk factors of childhood obesity [11-13], thus it could be beneficial to swap those snacks with a vegetables in order to increase intake but also improve the nutritional value of the meal. Yngve et al. [14] found that the majority of vegetables eaten by Danish children are raw, while the study of Moore et al. showed that children who received vegetables three times per day consumed more servings on average, while the increased frequency was associated with larger variety [9]. Therefore, using a raw vegetable afternoon snack seems to be an efficient and easy choice.

The most crucial aspect of children's fruit and vegetable intake seems to be their preferences $[15,16]$ and as vegetables are not an innately preferred food, children must learn to like them in order to achieve healthier nutrition habits [17-19]. It is suggested that early age food habits [20-22], as well as their protective or unfavourable effects [23,24], are likely to be preserved in adulthood, hence it seems important to establish a preference for fruits and vegetables from a young age. There are several strategies that have been developed in order to increase children's intake of fruit and vegetables, including flavour-nutrient learning, flavour-flavour learning and repeated exposure [25]. The latter supports that the preference for a specific food can be increased after repeated exposure to this initially unfamiliar food [25] and it has been successfully demonstrated [26-30]. Hausner et al. [31] showed that repeated exposure and flavour-flavour learning are useful strategies to change children's attitudes towards a novel vegetable, proposing even a long-term result, with repeated exposure being the most effective method, which is in line with Remy et al. [32]. The lack of complexity seems to give the strategy of repeated exposure an additional advantage [33].

Humans are genetically predisposed to prefer some of the basic tastes (sweet and salty) and reject others (bitter and sour) [18,34]. This can explain why vegetables are not among the favourite foods for children, as they contain several bitter compounds. Moreover, a polymorphism in the TAS2R38 gene might provoke a variability in the perception of bitterness of the compound 6-n-propylthiouracil (PROP) among the population, and it has been demonstrated that children with a lower PROP threshold (super-tasters) were less likely to try cruciferous vegetables [35]. Consequently, children have to learn to like this food group $[18,19]$, while it has been suggested that the optimum timing for this learning ability is from 4 months to 2 years old [36]. Parents are considered to be the basic factor forming their children's eating preferences in the first year of life [18], while the heritability of neophobia is also an interesting topic under study [26]. For kindergarten children, in addition to taste, texture seems to also be important in forming their food preferences [19,37], with the desired texture attributes also relying on cultural elements [38].

Neophobia, defined as "fear of the new", or the reluctance to try novel foods [39], also seems to be an obstacle for eating a varied diet $[17,40]$. Children with neophobia seem to consume a diet with less variety, that is, low mainly in vegetables, fruit and meat [41-47].

Picky eating is defined as the habitual rejection of either familiar or unfamiliar foods [48] which has, similarly to neophobia, the consumption of a diet low in variety as a consequence, usually poor in fruits and vegetables [49-52] as well as dietary fibre [50].

Both behaviours result in the toddler liking fewer kinds of fruits and vegetables but also trying fewer vegetables [53]. In general, food neophobia and picky eating lead to low diet diversity which is associated with decreased intake of micronutrients [54] and consequently the occurrence of nutritional deficiencies [55], and neophobic and picky children are reported to have a lower body weight $[51,56]$. However, it has been discussed that children with neophobic/picky behaviours might more easily accept some discretionary foods (energy dense and nutrient poor) due to their high palatability [57]. As they tend to reject healthy and non-energy-dense foods (such as vegetables) and often cover a larger part of their daily energy intake from these unhealthy, processed foods [58], it has been suggested that children with neophobic/picky behaviours can also be overweight and obese $[57,59]$. In other words, food neophobia and pickiness might be associated with both 
underweight and overweight or obese children [58], although there is a need for more evidence on this matter [57].

Food neophobia among toddlers has been linked to the pressure exerted from the parents on the child towards eating [60], while picky eating has been correlated with the dietary habits of the mother [59] and maternal feeding practices [61]. Actually, even though they are strongly correlated and share a common aetiology [62], picky eating is found to be mostly associated with environmental factors and experiences, compared to food neophobia which seems to also be influenced by individual parameters, such as genetic traits and temperament $[45,62,63]$. According to Nicklaus and Monnery-Patris, the traits of temperament are personal, rather stable, characteristics related to emotional and behavioural reactions [63]. The study of Moding and Stifter found that toddlers who are low on the approach dimension of temperament and tend to demonstrate negative effects and withdrawal responses to novel stimuli have increased chances to develop food neophobic behaviour during childhood [64]. Temperament includes inhibitory control, which is defined as the capacity to terminate, decrease or avoid a behaviour when instructed to do so, or when the circumstances are unfamiliar [65]. In the study of Rigal et al., the level of toddlers' inhibitory control was identified as a determinant of the impact of repeated exposure, with the children that had high inhibitory control being able to overcome their dislike of unfamiliar foods more easily during a five-session exposure intervention [66].

Repeated exposure is an effective strategy for the reduction of neophobia $[67,68]$ and it has been shown to also be negatively correlated with food pickiness [69]. It is defined as a replicated procedure where a stimulus is made approachable to an individual's perception of it [70]. The repetition of presenting the stimulus to the individual is the key in order for the individual to change her/his attitude towards the stimulus $[67,70]$. As stated in the review of Mura Paroche et al. [71], repeated exposure is an important way for young children to learn about food and increase familiarisation to foods or textures. The strategy has been examined thoroughly in the context of changing children's food preferences. An overview of exposure studies is provided in the Supplementary Materials (Tables S1-S6). From this, it is clear that studies vary substantially in setup, including exposure frequencies.

Most studies use a novel or a non-preferred food, aiming to increase the acceptance of it by repeatedly exposing children to it. Lakkakula et al. [27] proved that repeated taste exposures to poorly liked vegetables increased liking for most of them by elementary school children, while Maier et al. was able to demonstrate the same effect in infants [72]. According to Cooke [26], age is a determinant of the number of exposures needed to change the initial attitude, with older children requiring more exposures. This is in line with the study of Laureati, Bergamaschi and Pagliarini, which showed that a school-based exposure intervention was more effective in younger children [68]. As stated by Wadhera et al. [73], the effectiveness of this strategy on increasing liking for and intake of vegetables depends not only on age, but also on vegetable type. This is supported by Zeinstra et al. [29], who indicated that while repeated exposure is effective for increasing the intake of some vegetables, it might not be the best strategy for more familiar or blander tasting vegetables. Osborne and Forestell [74] studied if the type of exposure matters for the result, suggesting that repeated exposure, in the form of flavour exposures but also in the form of visual and informative cues of the stimuli through books, can be promising. In their study, children were exposed to two books, one about healthy eating and another one depicting drawings of fruits and vegetables, along with a taste exposure intervention. The exposure to books delivered positive results in increasing children's consumption of fruits they had not tasted yet in the taste exposure. However, the authors did not observe the same for vegetables. Ahern et al. [75] showed that children's liking of vegetables is related to the frequency of offerings of the vegetables, as they tend to like more the vegetables they are offered more often. This is in line with Grimm et al. [76] and Gregory et al. [77], who found that the less frequently the vegetables are offered during late infancy, the lower the intake during childhood. However, the impact of frequencies on the effectiveness of exposures is not 
yet clear as no more studies have investigated this subject to date, but a lot of exposure combinations seem to have succeeded.

On the other hand, it has been demonstrated that the liking and acceptance of a food might be reduced if it is consumed very often $[26-29,31,33,34]$ and this can make the specific food less preferred. According to the definition of "boredom", high familiarity with a food can decrease the desire to eat it [78]. This phenomenon is natural when using the strategy of repeated exposure as a consequence of the recurrent presentation of the stimulus [78]. According to Köster and Mojet [79], the level of complexity of the stimulus plays an important role in this process. The research editorial of Keller [80] discussed different intrinsic and extrinsic characteristics that influence the efficacy of the strategies used to improve children's acceptance of vegetables and which can vary within the population. Among others, early flavour experience at the foetus stage or during breastfeeding, as well as the way the vegetable is prepared and presented during the intervention, are important parameters to consider when designing a more personalised and efficient approach.

A further aspect which may affect food preferences is generalisation effects, which are when acceptance of a novel food reinforces the transfer to other non-exposed foods with similarities to the first one. The presence of such effects is not well documented, but Ahern et al. [81] suggested that repeated exposure can generalise to other similar vegetables, also depending on the preparation technique.

Moreover, the association of foods with the environment contributes to the forming of food preferences [82] and children select food affected by social impact in a positive or a negative way $[63,83]$. An interesting point is that it is possible to reduce the level of neophobia with positive peer modelling, thereby altering food preference [84].

Culture is an important aspect that affects acceptance of novel food, as the determinants of rejection have been found to vary between populations. The cross-cultural study of Sandvik et al. found different texture drivers of liking a high-fibre biscuit among children of different nationalities [38], while Estay et al. demonstrated that children of different origin varied significantly in their liking scores for six vegetables [85].

Aim of the Study

This study aimed at investigating different exposure frequencies and comparing their effectiveness on increasing the consumption of a novel vegetable by kindergarten children. The study also aimed at investigating whether there are generalisation effects from the exposures to other vegetables having more or less sensory characteristics in common with daikon.

The study was part of a larger study (Article "Optimising Repeated Exposure: Determining Optimal Stimulus Shape for Introducing a Novel Vegetable among Children"), sharing some experimental parts and groups, and in which a sensory profiling of the vegetables was made.

\section{Materials and Methods}

\subsection{Study Design}

Eight teams of kindergarten children were recruited for the study, six of each served as intervention teams and two served as control groups. Two of the intervention groups were exposed to the vegetable twice a week (2/week), the other two once a week (1/week) and the last two intervention teams were exposed on a bi-weekly basis. Assignment to the intervention groups was randomised. Three types of visits took place in the kindergartens: Two types of test visits and exposure visits. Pre- and post-control tests, conducted on two separate test days, were completed for all groups. The first visit included individual testing for liking, preferences and familiarity, while the second visit measured intake of the target vegetable. The six exposure groups underwent, in addition, seven exposure visits. The control intake session was set to be as close as possible to the exposure series, with the first exposure to start the week after the pre-test and the post-test to be completed the next week after the seventh exposure. The control groups did not receive any exposures. 
Follow-up sessions after 3 and 6 months, similar to the pre- and post-tests, were also completed for all eight teams. All the activities of the study were conducted in the subjects natural pre-school environment and in their mother language of Danish. The content of the different visit types is shown in Table 1.

Table 1. Overview of the content of the different visit types.

\begin{tabular}{cccc}
\hline Type of Visit & Groups & Test & Vegetable \\
\hline $\begin{array}{c}\text { Pre-test/baseline } \\
\text { measurement }\end{array}$ & All & Individual testing & $\begin{array}{c}\text { Familiarity and liking: Broccoli, } \\
\text { Cauliflower, Celeriac, Daikon } \\
\text { (round), Beetroot (round) }\end{array}$ \\
\cline { 2 - 4 } $\begin{array}{c}\text { Exposure twice } \\
\text { a week }\end{array}$ & All & Intake $(200 \mathrm{~g})$ & Daikon, round \\
\hline $\begin{array}{c}\text { Exposure once } \\
\text { a week }\end{array}$ & 1/week & Seven exposures $(100 \mathrm{~g})$ & Daikon, grated \\
\hline $\begin{array}{c}\text { Exposure once } \\
\text { every second week }\end{array}$ & Bi-weekly & Seven exposures $(100 \mathrm{~g})$ & Daikon, grated \\
\hline \begin{tabular}{c} 
Post-test \\
\cline { 2 - 4 }
\end{tabular} & All & Intake (200 g) & Daikon, grated \\
\cline { 2 - 5 } & All & Individual testing & $\begin{array}{c}\text { Familiarity and liking: Broccoli, } \\
\text { Cauliflower, Celeriac, Daikon } \\
\text { (round), Beetroot (round) }\end{array}$ \\
\hline 3-month follow-up & All & Intake (200 g) & Daikon, round \\
& All & Individual testing & $\begin{array}{c}\text { Familiarity and liking: Broccoli, } \\
\text { Cauliflower, Celeriac, Daikon } \\
\text { (round), Beetroot (round) }\end{array}$ \\
\hline 6-month follow-up & Individual testing & $\begin{array}{c}\text { Familiarity and liking: Broccoli, } \\
\text { Cauliflower, Celeriac, Daikon } \\
\text { (round), Beetroot (round) }\end{array}$ \\
\hline
\end{tabular}

\subsection{Recruitment and Participants}

Recruitment took place by inviting kindergartens in the greater area of Copenhagen to participate. Parents gave written, informed consent and children agreed to participate. After reviewing the protocol, the study was found not to require formal ethical approval by the Danish National Committee on Biomedical Research Ethics (ref. H-2-2011-FSP9). A reward of a DKK 50 (EUR 7) gift certificate for a Danish toy store was given as an incentive to the increase response rate on questionnaires.

Four different kindergartens with eight groups and a total of 193 children aged 3-6 years participated. The characteristics of the children are given in Table 2.

Table 2. Subjects' characteristics.

\begin{tabular}{ccccc}
\hline & Control & 2/Week & 1/Week & Bi-Weekly \\
\hline$n$ & 50 & 47 & 32 & 30 \\
Girls/boys & $23 / 27$ & $30 / 17$ & $14 / 18$ & $15 / 15$ \\
Age $^{1} \pm$ SEM & $51.8 \pm 2.0$ & $55.0 \pm 0.9$ & $53.8 \pm 2.1$ & $53.8 \pm 1.4$ \\
\hline
\end{tabular}

${ }^{1}$ Age is presented in months.

\subsection{Stimulus}

Daikon (also termed Chinese radish) is a part of cabbage family (Brassicaceae) [86]. It shares many aroma compounds with cauliflower, which is also white, and broccoli, which are members of the same family [87]. Beetroot and celeriac come from two different 
families, not associated with Brassicaceae [88]. Celeriac has colour similarities with daikon, while beetroot has not. In that manner, the vegetables were selected to have different levels of similarities with daikon based on taste and colour.

Daikon was chosen to be the target vegetable, as it was expected to be unfamiliar and neither liked nor disliked. Previously, 9-11-year-olds have rated daikon as neutrally liked [89], while it was also found to be one of the least preferred vegetables [90], a fact that provides the possibility of an increase in intake. Grated daikon was predicted to be the most unfamiliar serving style; hence, this form was served during the exposure visits. On the other hand, round slices of daikon were served during the baseline and post-test visits, as well as for the 3-month and 6-month follow-up.

The generalisation effect was examined by rating the liking of the children for four other vegetables: Cauliflower, broccoli, celeriac and beetroot, due to their several shared characteristics with daikon. Cucumber and celery were used as "dummy vegetables" in order to practice the use of the 3-point hedonic smiley scale that was used in the study, considering cucumber as a generally liked vegetable and celery as an unfamiliar and rather disliked one [90].

The selection of the target vegetable and the procedure of the study were established after a small pilot study in which 16 children took part. Daikon was rated as moderately liked, with an average liking score equal to 2.1 (on a scale from 1 to 3 , with 3 representing maximum liking of a stimulus), supporting the hypothesis that it would be a suitable vegetable to observe the improvements in liking and intake after the intervention.

\subsection{Visits with Individual Testing}

The individual testings were conducted in order to assess familiarity and liking of all the vegetables used in the study. These visits were carried out in the morning, before lunch time. The children were interviewed one-by-one by a trained assistant in a quiet area of the kindergarten. Familiarity was measured by showing each child a stick or floret of the assessed vegetable and noting on the questionnaire whether they had tasted the specific vegetable before. The 3-point hedonic smiley scale was used for the evaluation of liking and preference, as it has been previously demonstrated that it can be successfully used with 3-year-old children [91-94]. The scale was presented, explained and practiced with the children before the tasting. This was achieved by asking the children to first rank some favourite foods and, following that, using the dummy vegetables. Liking was measured by asking the child to taste the vegetable used for familiarity testing and score it on the smiley scale. The evaluation of the reference vegetables (broccoli, cauliflower and celeriac presented in random order) was first completed, before the assessment of beetroot and daikon, both served as random slices and following a randomised order. Every child had the choice not to try a vegetable or not to participate at all. All the answers of the children were noted down on a questionnaire.

\subsection{Intake Visit}

During this visit, the children were served $100 \mathrm{~g}$ of round sliced daikon in a preweighed plastic beaker as an afternoon snack, sitting all together. The subjects were instructed to eat as much as they liked and ask for a second serving of $100 \mathrm{~g}$ if they wished (maximum intake $200 \mathrm{~g}$ ), while they were not allowed to share their beaker or comment on the food. In addition, it was possible to accompany this snack with water or milk. After the children finished eating the vegetable, the amount consumed was calculated by weighing the beakers on a scale with $0.1 \mathrm{~g}$ precision (Sartorius Gram TE15025, Sartorius AG, Göttingen, Germany).

\subsection{Exposure Visit}

The conduction of the exposure visit followed the very same procedure as the intake visit, with the beakers this time containing $100 \mathrm{~g}$ of grated daikon and without offering a second serving (maximum intake $100 \mathrm{~g}$ ). The children were provided with a child-sized 
fork in order to eat the grated vegetable, and the headspace within the serving beakers was refreshed prior to serving to minimise smell. After each exposure visit, the beakers were weighed again on a calibrated precision scale to calculate the amount of the vegetable eaten by the children.

\subsection{Samples}

All vegetables were delivered by K.C. Frugt (Valby, Denmark) and stored at $5{ }^{\circ} \mathrm{C}$. The different shapes were already processed (round sliced and grated) but they were slightly modified in order to achieve a perfectly round shape or to check for brown colouring. All vegetables were put in the beakers the same day of the kindergarten visit. The lid of each beaker was marked with the name of a child.

\subsection{Questionnaire}

At the beginning of the intervention, children's parents were asked to fill out a 16-page-long questionnaire which included questions about the child and the parents. Fruit and vegetable consumption, general eating habits ("Children's Eating Behaviour Questionnaire" [95]; "Comprehensive Feeding Practices Questionnaire" [96]), child's liking and familiarity of the vegetables used in the study, as well as the Food Neophobia Scale adjusted for children [43,97], were covered.

\subsection{Data Analysis}

The data were analysed using the open-source software RStudio (Version 1.2.5019 (C) 2009-2019 RStudio, Inc., Boston, MA, USA), while Microsoft Excel (Version 16.26 (20091400) (C) 2020 Microsoft Corporation, Redmond, WA, USA) was used to structure the data, calculate the standard deviation (SD) and standard error of the mean (SEM) and prepare the plots. For the subjects of the exposure groups, an exclusion criterion was implemented; a child was excluded from the data analysis if he/she participated in fewer than four of the seven exposure sessions.

The influence on the liking of daikon and other vegetables of the different exposure frequencies was studied using the R packages nlme [98] and multcomp [99]. The first was used to run the linear mixed model (lme function) and the second in order to calculate the difference of the differences between and within the exposure and control groups for each session (glht function). The initial model contained random and fixed factors, such as age and gender, as well as kindergarten institution, which were not found to be significant and thus they were excluded during the validation of the models. The reduced model used was simple and included only fixed factors and an interaction term for exposure frequency and timing.

The intake of daikon during the control sessions (pre-test, post-test, 3-month follow-up and 6-month follow-up) was associated with the various exposure frequencies using the same R packages mentioned above, nlme and multcomp. The linear mixed model was run using the function lmer, while the glht function was used to calculate the difference of the differences and extract the $p$-values. This model was used without reduction in the analysis, and it contained both fixed and random factors, as well as an interaction term for exposure frequency and timing. The fixed factors were baseline daikon liking, baseline familiarity to daikon, age and gender, and the random factors were participants' ID number, group and kindergarten institution. The average intake of daikon during the seven exposure sessions was analysed similarly.

All $p$-values are taken from RStudio from the output of $g l h t$ function.

\section{Results}

\subsection{Subject Characteristics}

As shown in Table 2, age and gender distributions were different in the four groups, but in the analyses, no significant age or gender effect was found. Thirty-four of the 
193 children who took part in the study were excluded from data analysis as they were present in less than four exposures, leaving the data of 159 subjects for the analysis.

The information obtained from the questionnaires was in the end not used in the analyses, as the response rate of the parents led was too low (61\%).

\subsection{Test Visits}

\subsubsection{Liking}

Overall, there is an increasing tendency for liking of daikon throughout the duration of this study, that is observed for all groups. Figure 1 illustrates the liking score for daikon between groups and within groups in the different control sessions (baseline, postintervention, 3-month follow-up and 6-month follow-up). The significant differences that occurred from data analysis concern all the exposure groups, as well as the control group.

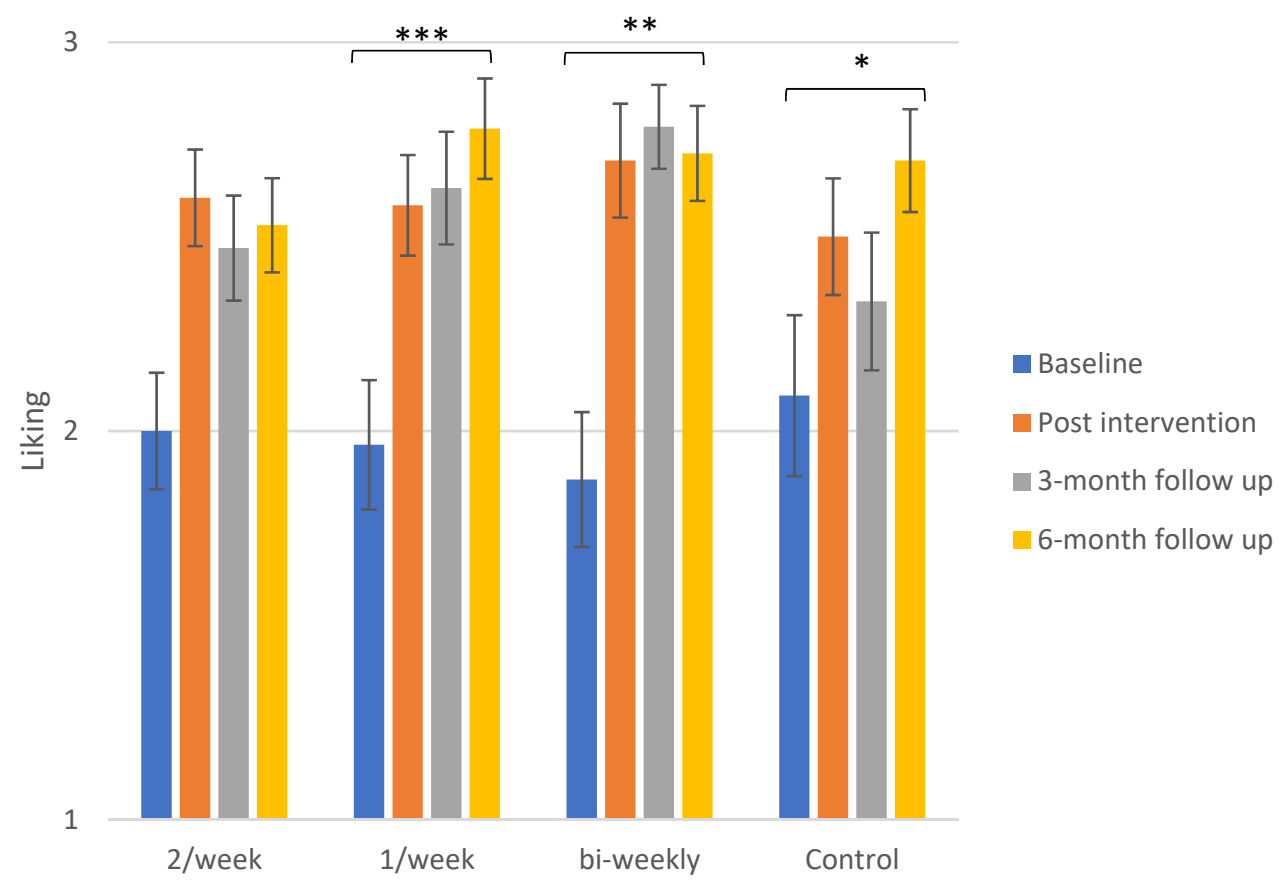

Figure 1. Mean liking scores \pm SEM of daikon for the different exposure groups and control groups for the four control visits. The significance of the overall differences only (baseline to 6-month follow-up) for the groups of 1 /week and bi-weekly exposure and the control group is depicted. The overall increase in liking of daikon was not found to be significant for the group that received daikon $2 /$ week. The detailed differences and their statistical significance are given in the text. Significance levels: ${ }^{\prime * * * \prime}: \leq 0.001,{ }^{\prime * * \prime \prime}: \leq 0.01,{ }^{\prime * \prime \prime}: \leq 0.05$.

\section{Control Group}

Liking for daikon increased from baseline to post-intervention from $2.0 \pm 0.2$ to $2.5 \pm 0.2$, although this increase was not significant. A drop was observed at 3-month follow-up (2.3 \pm 0.2$)$ but the liking rose at 6-month follow-up, reaching its peak for the control group $(2.7 \pm 0.1)$, a value that is significantly higher than liking at baseline $(p \leq 0.05)$.

\section{Exposure Groups}

It seems that there are significant differences between daikon liking at baseline and most of the following control sessions for the children who received grated daikon in every exposure frequency, while the kinetics slightly vary among the groups.

For the subjects that received daikon twice per week, liking developed from $2.0 \pm 0.1$ of baseline to $2.6 \pm 0.1$ post-intervention $(p=0.001)$ and slightly dropped to reach $2.5 \pm 0.1$ at 3-month follow-up. The value of daikon liking for the 6-month follow-up remained 
rather stable $(2.5 \pm 0.1)$. The difference between baseline and 6-month follow-up was not found to be significant, as the $p$-value exceeded 0.05 .

The exposure group that tasted daikon once per week expressed a steady increase in liking for the vegetable, as it rose from baseline $(2.0 \pm 0.2)$ to post-intervention $(2.6 \pm 0.1$, $p \leq 0.001)$ and this remained almost stable at the 3-month follow-up (2.6 \pm 0.2$)$ but further increased at 6 months $(2.8 \pm 0.1)$. The increases recorded from baseline to 3- and 6-month follow-up were also found to be significant $(p \leq 0.001)$.

The subjects exposed to the vegetable every two weeks showed a larger increase in the liking for daikon, from $1.9 \pm 0.2$ at baseline to $2.7 \pm 0.2$ post-intervention $(p=0.005)$, that further rose to $2.8 \pm 0.1$ at 3 months and returned to $2.7 \pm 0.1$ at 6-month follow-up, with the overall difference (baseline to 6-month follow-up) found to be statistically significant $(p \leq 0.01)$.

In all groups, including the control group, the liking score was elevated at 6-month follow-up compared to baseline, indicating that even the low frequency and small quantity of the control group may be sufficient to significantly improve the acceptance of an unfamiliar vegetable. The changes between the initial control session and the 6-month follow-up were found to be statistically significant for all groups except for the group that received daikon twice per week. The liking of the vegetable in this group was effectively increased in the short term but was followed by a slight decrease, which was maintained in the long term (3 and 6 months), leading to a difference that was overall not significant. This pattern was somewhat also followed by the bi-weekly group concerning the 6-month follow-up, although the total increase was found to be significant for this group. A boredom effect could explain the first case, as the subjects were exposed to daikon more frequently, but not for the lower frequency of exposure. Overall, it seems that the highest liking value at 6-month follow-up was obtained by the subjects that were exposed once per week to the vegetable $(2.8 \pm 0.1)$, while it is important to note that the control group, receiving daikon just in the test sessions, achieved almost the same value at 6 months $(2.7 \pm 0.1)$.

\subsubsection{Intake}

Intake in test sessions is shown in Figure 2. Intake of daikon was elevated from baseline to the following sessions in all groups, including the control group. Significant differences were found for the children who were exposed to the vegetable at any frequency but also for the control group, from baseline to post-intervention, baseline to 3-month follow-up and baseline to 6-month follow-up.

\section{Control Group}

The initial intake of $13 \pm 4 \mathrm{~g}$ at baseline rose to $35 \pm 7 \mathrm{~g}$ at post-test, $54 \pm 8 \mathrm{~g}$ at 3 months and $85 \pm 11 \mathrm{~g}$ at 6 months, with all these differences found to be significant $(p=0.002, p \leq 0.001$ and $p \leq 0.001$, respectively).

\section{Exposure Groups}

For the exposure group that received daikon twice per week, intake increased from $30 \pm 3 \mathrm{~g}$ at baseline to $61 \pm 5 \mathrm{~g}$ post-intervention. The value slightly dropped at 3-month follow-up (54 $\pm 5 \mathrm{~g}$ ) but reached a peak at 6-month follow-up (110 $\pm 6 \mathrm{~g}$ ), which is the highest intake among all groups. The differences between baseline and all the other sessions were found to be statistically significant ( $p=0.03, p=0.02$ and $p \leq 0.001$, respectively).

The subjects that tasted the target vegetable once per week demonstrated the lowest initial mean intake $(9 \pm 2 \mathrm{~g})$, which rose to $64 \pm 8 \mathrm{~g}$ after the intervention $(p \leq 0.001)$, dropped at 3 months ( $40 \pm 8 \mathrm{~g}$ ) and peaked at 6 months ( $82 \pm 15 \mathrm{~g})$. Similarly to the other groups, the overall change was found to be statistically significant $(p \leq 0.001)$.

The children that were exposed to daikon once every two weeks showed a substantial increase in intake from baseline $(15 \pm 5 \mathrm{~g})$ to post-intervention $(75 \pm 13 \mathrm{~g})$ that continued to rise at 3 months $(82 \pm 13 \mathrm{~g})$ and at 6 months $(90 \pm 11 \mathrm{~g})$, with intake for all these sessions found to be significantly higher than baseline intake $(p \leq 0.001)$. 
The total increase in intake from baseline to 6-month follow-up ranged around 70-80 $\mathrm{g}$ for all groups, indicating that the results of all frequencies and control were comparable in terms of quantity.

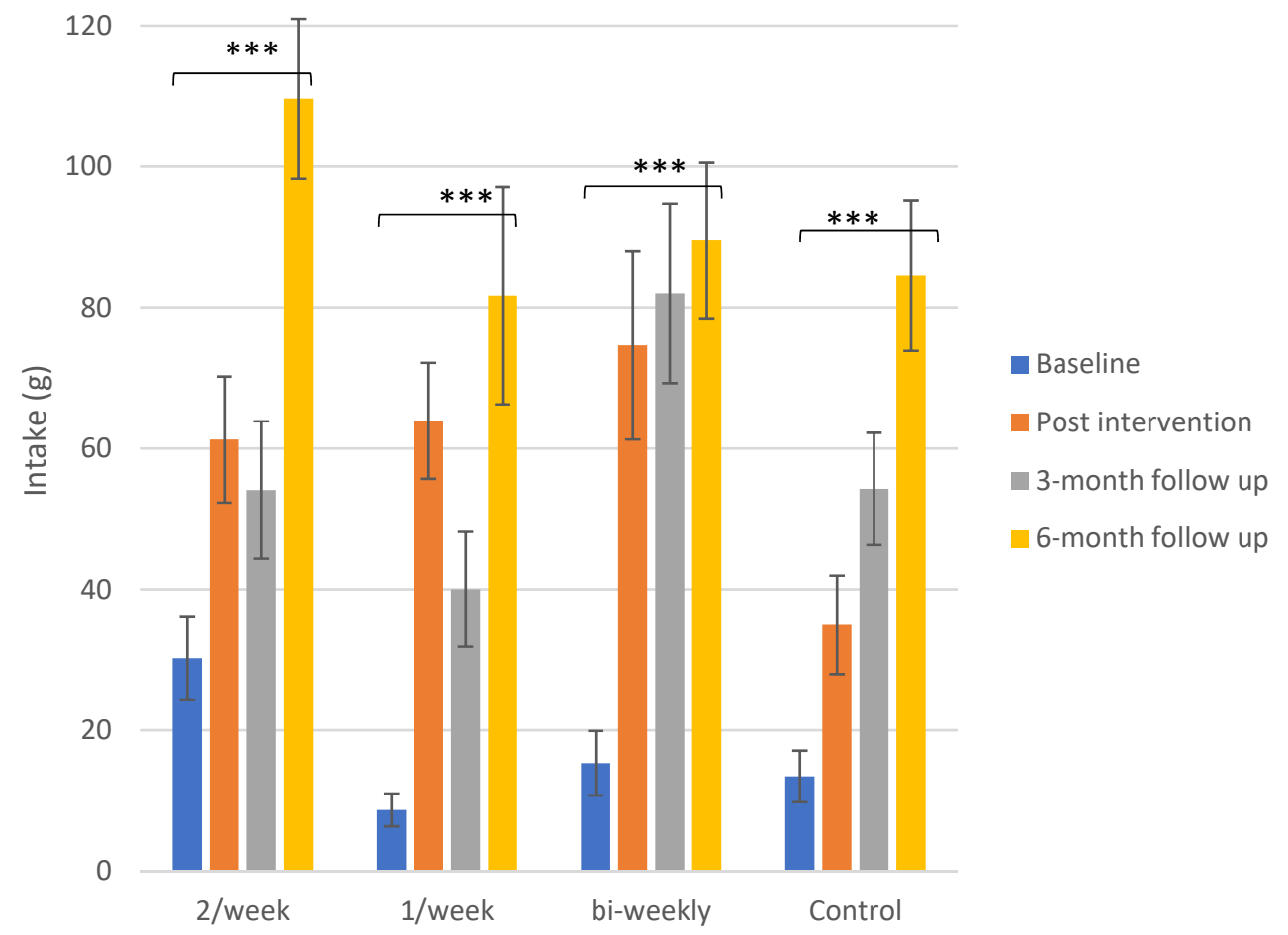

Figure 2. Mean intake scores \pm SEM in $g$ of daikon for the different exposure groups for the control visits. The significance of the overall differences only (baseline to 6-month follow-up) for the groups of $2 /$ week, 1 /week and bi-weekly exposure and the control group is depicted. The detailed differences and their statistical significance are given in the text. Significance levels: '***': $\leq 0.001$.

\subsection{Exposure Visits}

All exposure groups demonstrated an increase in intake from the 1st to the 7th exposure, as shown in Figure 3, following quite similar tendencies.

For the exposure group that received daikon once per week, intake increased until the 6th exposure, when it reached a peak (mean intake of $42 \pm 8 \mathrm{~g}$ of daikon). The analysis revealed significant differences between the 1 st and the $3 \mathrm{rd}(p \leq 0.001), 4$ th $(p \leq 0.001)$, 5th $(p \leq 0.001)$, 6th $(p \leq 0.001)$ and 7 th $(p=0.02)$ exposure as well between the 2 nd and the $3 \mathrm{rd}$ $(p=0.014), 4$ th $(p=0.006), 5$ th $(p=0.02)$ and 6 th $(p=0.05)$ exposure.

Children exposed to daikon twice per week showed an increase in intake until the 4th exposure ( $56 \pm 4 \mathrm{~g}$ ) and afterwards a slight drop in the 5th exposure, and the average intake manifested a rather similar but highest level for the group at the 6 th one (57 $\pm 8 \mathrm{~g})$. The measurement that took place during the final exposure session was lower $(42 \pm 4 \mathrm{~g})$, a value that was found to be significantly different to the ones of the 4 th $(p \leq 0.001)$ and 6th exposure $(p=0.007)$, but not significantly higher than the initial exposure session. The data analysis for this group showed significant differences between the 1 st and the 4 th $(p \leq 0.001)$ and 6th exposure $(p=0.0015)$, as well as the 2 nd and the 4 th $(p \leq 0.001)$ and 6 th exposure $(p=0.0015)$.

The group which received daikon bi-weekly demonstrated an almost steady increase until the 5th exposure and, after a decrease, a peak at the 7th exposure (68 $\pm 8 \mathrm{~g})$, which is also the highest level of intake found among all groups and all exposure sessions. The differences between average intake of the 1st exposure were found to be significant compared to the 2 nd $(p=0.01)$, the $3 \mathrm{rd}(p \leq 0.001)$, the 4 th $(p \leq 0.001)$, the 5 th $(p \leq 0.001)$ and the 6th $(p \leq 0.001)$, as well as the comparison between the 2 nd and the 3rd $(p=0.003)$, the 4 th $(p \leq 0.001)$, the 5 th $(p \leq 0.001)$, the 6 th $(p=0.005)$ and the 7 th $(p \leq 0.001)$ exposure. 
The difference between the 1st and the 7th exposure was also found to be significant, increasing from $7 \pm 3 \mathrm{~g}$ to $68 \pm 8 \mathrm{~g}$ of daikon $(p \leq 0.001)$.

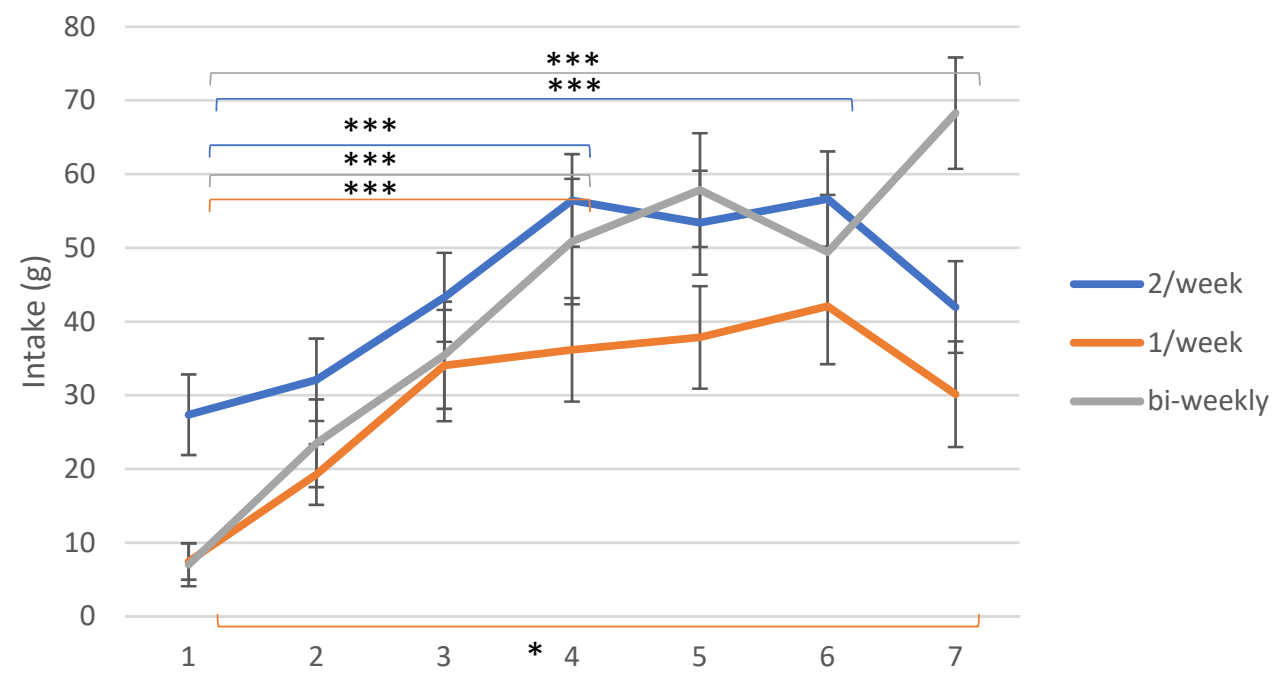

Figure 3. Mean intake scores \pm SEM in $g$ of daikon of the different intervention groups for each exposure session (1-7). The significance of the differences between selected sessions is depicted for all exposure groups. All groups showed a significantly higher intake at the 4 th and the 7 th exposure compared to the 1st one. The detailed differences and their statistical significance are given in the text. Significance levels: ${ }^{(* * * \prime}: \leq 0.001,^{(* \prime}: \leq 0.05$.

For the two first groups (1/week and 2/week) we can highlight that intake in the final exposure was lower compared to previous exposures. On the contrary, children in the bi-weekly group consumed more daikon in the 7th exposure after demonstrating a significant reduction from the 5 th to the 6 th $(p<0.05)$ exposure session. This could indicate that more frequent exposure can lead to boredom, while a lower frequency of the vegetable actually led to the highest intake in the last exposure (68 $\pm 8 \mathrm{~g}$ compared to $30 \pm 7$ and $42 \pm 4 \mathrm{~g}$ for 2 /week and 1 /week, respectively).

\subsubsection{Exposures $1-4$}

If we take into account the 4th exposure as a benchmark, we can observe that intake follows a continuous increase from the 1st until the 4th exposure for all the exposure groups, with the group that received daikon twice per week demonstrating the highest intake at that point.

\subsubsection{Exposures $4-7$}

After the 4th exposure, the average intake measurements follow a different pattern, with all the exposure groups reaching a plateau in different exposure sessions. The exposure groups of 1/week and 2/week recorded their peak level in the intake measurement at the 6th exposure and the group with a bi-weekly frequency at the 7th exposure.

To complement the above, we also need to evaluate intake during the follow up sessions, in order to conclude which frequency had an effect that lasted longer. At the 6-month follow-up, children exposed to daikon twice per week demonstrated the highest level of intake (110 $\pm 6 \mathrm{~g})$, while liking at the same point showed the lowest score among the other groups (these differences in liking were not significant between groups). The children exposed to the vegetable once every two weeks had a mean consumption of $90 \pm 11 \mathrm{~g}$. The other two exposure groups showed a slightly lower intake for this session, with the intake of the control group at this session found to be slightly higher than that of the 1 / week exposure group. 


\subsection{Generalisation Effects}

Daikon is a member of the cabbage family (Brassicaceae), as are broccoli and cauliflower. Beetroot and celeriac were also used to study the possibility of a generalisation effect of the daikon exposures. They share some common aroma compounds, although they do not originate from the same family.

Cucumber and celery were used as dummy vegetables in order to test the three-point smiley hedonic scale. Cucumber is a generally liked vegetable, a fact shown by its liking score which almost reaches 3 , while celery is a generally unfamiliar vegetable and its liking score remained below 2 in this study (Figure 4).

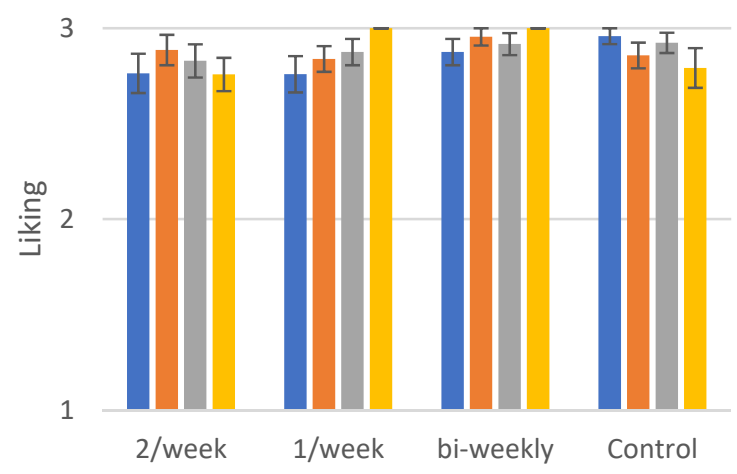

(a)

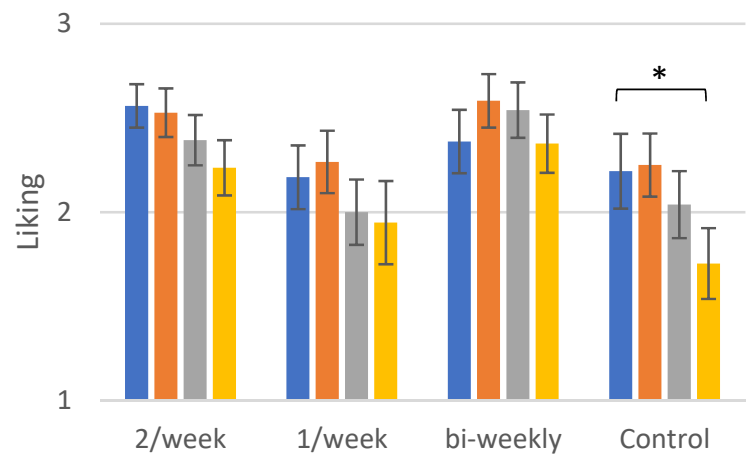

(c)

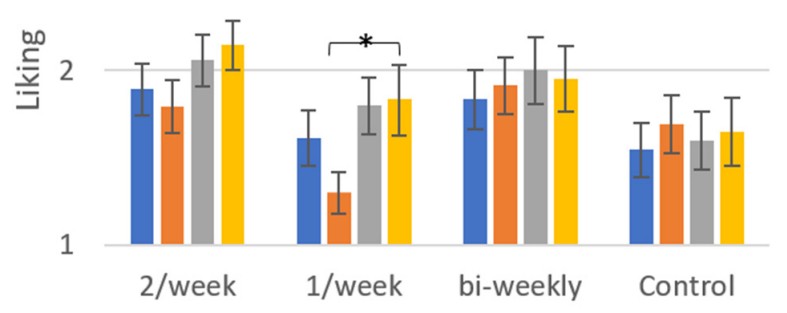

(e)
3

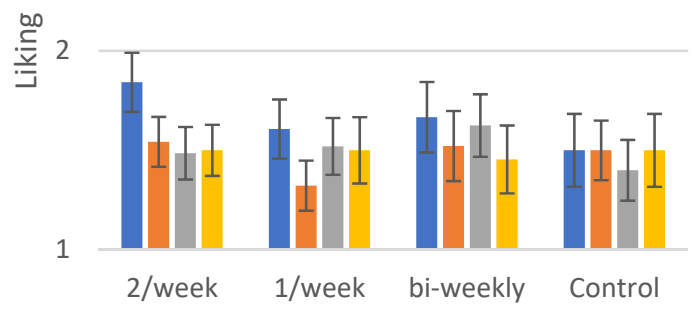

(b)

3

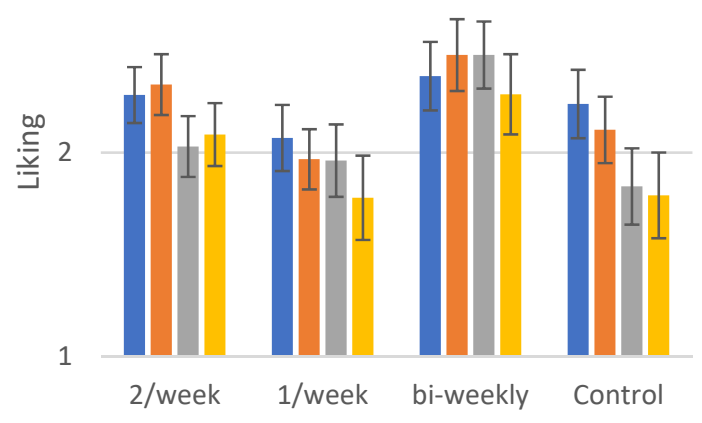

(d)

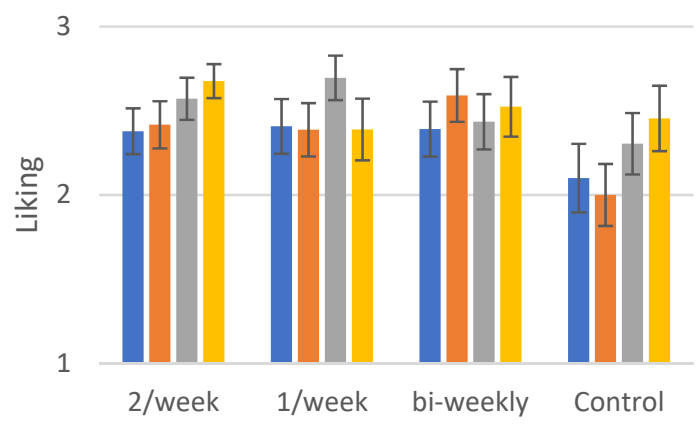

(f)

Figure 4. (a) Liking of cucumber for the different groups. (b) Liking of celery for the different groups. (c) Liking of broccoli for the different groups. (d) Liking of cauliflower for the different groups. (e) Liking of celeriac for the different groups. (f) Liking of beetroot for the different groups. Liking scores \pm SEM of the different vegetables measured in control sessions for each group in order to investigate the presence of transfer effects. The significance of the differences between selected sessions is depicted for all exposure groups and vegetables. The detailed differences and their statistical significance are given in text. Significance levels: ' ${ }^{* \prime}: \leq 0.05$. 
Figure $4 \mathrm{a}-\mathrm{f}$ illustrate the liking of the different vegetables as measured in the control sessions. No significant differences were found for these vegetables in liking scores after the exposure of the children to Chinese radish, except for celeriac and beetroot. Celeriac was found to be liked significantly more at the 3-month follow-up (1.8 \pm 0.2$)$ compared to post-intervention $(1.3 \pm 0.1)$ for the group that was exposed to daikon once per week $(p \leq 0.05)$. There was also a significant difference in the liking of the celeriac at 3-month follow-up between the exposure group that received daikon twice per week and the control group $(p \leq 0.05)$. Concerning beetroot, liking was significantly higher post-intervention for the group that was exposed bi-weekly to daikon compared to the control group $(p \leq 0.05)$, while the latter showed a lower score at 3-month follow-up compared to the group that received daikon once per week $(p \leq 0.05)$. However, these results are not demonstrated systematically in this study and, therefore, we cannot conclude on a generalisation effect of exposure to daikon towards other vegetables.

The subjects of the control group also showed significant differences in liking of broccoli at baseline and 6-month follow-up $(p \leq 0.05)$ and post-test and 6-month follow-up $(p \leq 0.05)$. This is potentially connected to the small amounts of the vegetable that the children received during the control sessions, in line with the results for daikon that were discussed above.

\section{Discussion}

This intervention study aimed to explore the difference in the effectiveness of various exposure frequencies in improving liking and intake of a novel vegetable in kindergarten children.

\subsection{Exposure Frequency}

As shown in Table S1, there is a variety of intervention studies using the repeated exposure strategy towards increasing liking and acceptance of novel vegetables by children. The variability between these results of repeated exposure could be explained by different factors, such as the different serving styles and settings and the differences of initial liking of the vegetable, as well as the target food itself. The results of the present study are in line with many previous studies that found repeated exposure to be effective in toddlers and children [27,28,30,31,68,81,100-109]. The initial liking of the target vegetable was relatively low (with the mean score of most groups close to 2 ), which provided a potential window of improvement throughout the intervention period.

From the results of this study, it is seen that more frequent exposure led to more rapid changes, as the groups that received daikon once and twice per week demonstrated a steeper increase during the seven-exposure period which, nevertheless, reached a plateau and dropped by the 7th exposure. The groups with the more frequent exposure show a drop and peak levels of intake during the intervention slightly earlier than the group receiving daikon bi-weekly. This could suggest that more frequent exposures seem to deliver faster results, but indicating that the levels of boredom could also be more elevated in these cases. However, while the bi-weekly group demonstrates the highest level of intake in the final exposure session, the intakes reported at the 6-month follow-up for the different exposure groups are not significantly different $(p>0.05)$.

The kinetics of intake during the seven exposure sessions contradict the findings of Cooke, who suggested that in order to accept a novel vegetable, children need to be exposed to it 5-15 times [26], and the systematic review and meta-analysis of Nekitsing et al., who proposed at least 8-10 exposures [30]. In this study, one can observe that intake levels reach a plateau around the 4th-6th exposure for all groups, indicating that a smaller number of exposures might be a better idea in order to prevent boredom, a phenomenon that is well known to occur after a large number of exposures [34,110]. This is in agreement with the study of Caton et al., who found that as few as five exposures were adequate for toddlers to accept a novel vegetable purée [101]. 
It is interesting to combine the above with the pattern that the control group follows, as we can come to the conclusion that small quantities of the stimuli are sufficient to increase liking and intake. It should be noted that the control group of this study was not a "neat" control group, as it received some daikon on the control sessions (baseline, post-intervention, 3-month follow-up and 6-month follow-up) in order to evaluate liking and measure intake. The control group of course did receive a smaller amount of the vegetable in total as it was not part of the seven exposure sessions; thus, it seems that even this small amount and the low frequency of exposure to daikon had, as a result, an increase in both liking score and intake at 6 months. This shows that parents can see results in their child's intake even if they present the vegetable in small quantities and at a flexible frequency.

Summing up, the boredom effect is not demonstrated clearly in this study in the long term, while it seems in general that all frequencies deliver comparable results.

\subsection{Generalisation Effects}

Some evidence for generalisation effects were seen. Grated daikon was used as the intervention stimulus, and sliced daikon during test days. Liking and intake increased for both stimulus types, which may be interpreted as generalisation effects taking place within the same stimulus type, i.e., the same stimulus may be served in different ways during exposures and still contribute to increased acceptance. However, no systematic generalisation effects were seen for the other types of vegetables. Similar findings were seen in the parallel study on the effect of the serving style of daikon Article "Optimising Repeated Exposure: Determining Optimal Stimulus Shape for Introducing a Novel Vegetable among Children"). Previous studies investigating generalisation effects did not show consistent findings, thus the effectiveness of repeated exposure in increasing liking of other similar foods is not yet clear. Ahern et al. [81] observed an increase in children's acceptance and intake of a different stimulus that shared similar characteristics to the ones they had been exposed to, which is in agreement with Birch and Loewen [111,112]. On the other hand, Olsen et al. and Hetherington et al. $[89,113]$ could not demonstrate the effect. The vegetables used in the study were chosen strategically to have shared characteristics with the target vegetable, in agreement with Birch et al. [82], who suggested that the generalisation effect is more evident in similar stimuli. Nevertheless, the results of the present study were unable to show a concrete generalisation for the control vegetables.

\subsection{Limitations}

A limitation in this study is potential increases in intake due to children growing throughout the duration of this study and thereby increasing their consumed amounts. Although this applies to all experimental groups, it is particularly relevant for the group with exposures every second week, as their exposure period covers a longer time period. Including an additional age-matched control group to be tested only before the intervention and at 6-month follow-up could be a potential solution to this limitation for future studies.

As demonstrated in the sensory profiling study Article "Optimising Repeated Exposure: Determining Optimal Stimulus Shape for Introducing a Novel Vegetable among Children"), the different shapes of daikon show distinct sensory characteristics. The round shape used in the intake evaluation was found to be sweeter than the grated daikon used in the individual testings and the exposure sessions and which was characterised as bitter and pungent. This variability of the sensory attributes could have affected the consistency of the results between the different types of visits. Furthermore, the use of round daikon at test visits may have reduced recognition somewhat and resulted in lower scores for liking and intake than might have been seen if the test stimulus was grated daikon, as used during exposures.

The control group tasted both grated (individual testings) and round (intake evaluation session) daikon during the control visits, presenting a low frequency of exposure to the vegetable. This fact led to the positive conclusion that even small amounts and 
a low frequency and tasting of an unfamiliar vegetable can deliver results in terms of children's acceptance.

The maximum intake level during the control visits ( $200 \mathrm{~g})$ was different compared to the exposure visits $(100 \mathrm{~g})$, a fact that complicates the comparison of the amounts of daikon consumed. The average intake at control visits might have been increased due to those children who ate more than one portion of daikon.

Finally, it should be noted that other findings may be obtained using other exposure frequencies, stimulus types and age groups.

\section{Conclusions}

The findings in this study on optimum exposure frequency to an unfamiliar vegetable were not clear. All exposure frequencies lead to an increase in liking and intake of daikon, with the more frequent ones possibly displaying more rapid outcomes but also reaching a plateau in intake faster than a low exposure frequency. Due to the positive outcomes of the control group, even low frequencies may provide positive changes in acceptance and the exposed quantity does not necessarily need to be large. No evidence for systematic generalisation effects was found.

\section{Implications}

The findings from this study can easily be applied and implemented at home and in institutional settings, as it seems that repeated exposure is indeed an effective strategy to increase liking and intake of a novel vegetable for children 3-6 years old. Among the frequencies tested, they were all sufficient, and none in particular can be recommended as optimal. This supports a large amount of flexibility among parents and caregivers to introduce unfamiliar vegetables at a frequency convenient to the cooking schedule, time and place, without adhering to particular frequencies to do so. Interestingly, even a few infrequent exposures given over a long time seem to be sufficient; a promising result for parents who want to succeed in vegetable acceptance of their children with a few exposures. It is important to keep in mind that the home food environment may act as a mediator of such intervention effects, with caregivers' fruit and vegetable intake playing an important role as well [114].

Since generalisation effects were not found, parents and caregivers wanting to increase liking and acceptance of novel vegetables should bear in mind that this requires presenting each vegetable on its own, as it cannot be expected that exposing children to one vegetable will generalise to others.

Supplementary Materials: The following are available online at https:/ /www.mdpi.com/article/10 $.3390 /$ foods10050913/s1, Table S1: Studies using mere exposure to increase intake/liking in infants ( $<12$ months). The studies are sorted according in ascending to publication year. Success-column: an evaluation of the effect of mere exposure; + : clear effect, $(+)$ : some effect but not clear, -: no effect. Table S2: Studies using mere exposure to increase intake/liking in toddlers and children (>12 months -17 years). The studies are sorted according in ascending to publication year. Table S3: Studies using mere exposure to increase intake/liking in young adults and adults ( $>18$ years). The studies are sorted according in ascending to publication date. Suc-cess-column: an evaluation of the effect of mere exposure; +: clear effect, $(+)$ : some effect but not clear, -: no effect. Table S4: Studies using mere exposure to increase intake/liking (recalled/retrospective data). The studies are sorted according in ascending to publication date. Success-column: an evaluation of the effect of mere exposure; +: clear effect, (+): some effect but not clear, - : no effect. Table S5: Studies using visual mere exposure to increase intake/liking). The studies are sorted according in ascending to publication date. Success-column: an evaluation of the ef-fect of mere exposure; +: clear effect, $(+)$ : some effect but not clear, -: no effect. Table S6: Studies using hands-on mere exposure to increase intake/liking. The studies are sorted according in ascending to publication date. Success-column: an evaluation of the effect of mere exposure; +: clear effect, $(+)$ : some effect but not clear, $-:$ no effect.

Author Contributions: Conceptualisation, P.M., H.H. and A.O.; methodology, P.M., H.H. and A.O.; formal analysis, K.K. and C.R.; investigation, L.G.H.J. and E.H.T.; resources, P.M., H.H. and A.O.; data 
curation, L.G.H.J., E.H.T., H.H. and A.O.; writing—original draft preparation, K.K.; writing-review and editing, all authors.; visualisation, K.K.; supervision, A.O.; project administration, P.M., H.H. and A.O.; funding acquisition, P.M. All authors have read and agreed to the published version of the manuscript.

Funding: The study was funded by the European Community's Seventh Framework Programme (FP7/2007-2013) under the Grant Agreement No. FP7-245012-HabEat, and the research was further supported by Nordea-fonden as part of the project "Taste for Life".

Institutional Review Board Statement: After reviewing the protocol, the study was found not to require formal ethical approval by the Danish National Committee on Biomedical Research Ethics (ref. H-2-2011-FSP9).

Informed Consent Statement: Informed consent was obtained from the parents of all children that participated in the study.

Data Availability Statement: Data is not avaible for sharing.

Conflicts of Interest: The authors declare no conflict of interest.

\section{References}

1. Ovesen, L.; Andersen, L.N.; Dragsted, L.O.; Godtfredsen, J.; Haraldsdóttir, J.; Stender, S.; Sølling, K.; Tjønneland, A.; Trolle, E. Frugt, Grønt Og Helbred. Opdatering Af Vidensgrundlaget; Fødevareinstituttet DTU: Søborg, Denmark, 2002.

2. WHO. Increasing Fruit and Vegetable Consumption to Reduce the Risk of Noncommunicable Diseases; World Health Organization: Geneva, Switzerland, 2017.

3. Appleton, K.M.; Hemingway, A.; Saulais, L.; Dinnella, C.; Monteleone, E.; Depezay, L.; Morizet, D.; Armando Perez-Cueto, F.J.; Bevan, A.; Hartwell, H. Increasing Vegetable Intakes: Rationale and Systematic Review of Published Interventions. Eur. J. Nutr. 2016, 55, 869-896. [CrossRef] [PubMed]

4. Astrup, A.; Andersen, N.L.; Stender, S.; Trolle, E. Spis Frugt Og Grønt—6 Om Dagen. In Kostrådene 2005; Ernæringsrådet og Danmarks Fødevareforskning: Søborg, Denmark, 2005; pp. 21-27.

5. Pedersen, A.N.; Fagt, S.; Groth, M.V.; Christensen, T.; Biltoft-Jensen, A.; Matthiessen, J.; Andersen, N.L.; Kørup, K.; Hartkopp, H.; Ygil, K.H.; et al. Grøntsager Og Grøntsagsprodukter Samt Frugt Og Frugtprodukter. In Danskernes Kostvaner 2003-2008: Hovedresultater; Fødevareinstituttet DTU: Søborg, Denmark, 2010; pp. 30-34.

6. Norden. Nordic Nutrition Recommendations 2012: Integrating Nutrition and Physical Activity, 5th ed.; Nordisk Ministerråd: Copenhagen, Denmark, 2014.

7. Fødevarestyrelsen. De Officielle Kostråd-Godt for Sundhed og Klima. Available online: https://altomkost.dk/raad-oganbefalinger/de-officielle-kostraad-godt-for-sundhed-og-klima/ (accessed on 20 January 2021).

8. Svastisalee, C.; Krølner, R.; Pedersen, T.P.; Rasmussen, M. Kostvaner. In Skolebørnsundersøgelsen 2010; Statens Institut for Folkesundhed, Syddansk Universitet: Odense, Denmark, 2011.

9. Fayet-Moore, F.; McConnell, A.; Cassettari, T.; Tuck, K.; Petocz, P.; Kim, J. Vegetable Intake in Australian Children and Adolescents: The Importance of Consumption Frequency, Eating Occasion and Its Association with Dietary and Sociodemographic Factors. Public Health Nutr. 2020, 23, 474-487. [CrossRef] [PubMed]

10. Christensen, L.M.; Kørup, K.; Trolle, E.; Matthiessen, J.; Fagt, S. Børn Og Unges Måltidsvaner 2005-2008; DTU Fødevareinstituttet, 2012. Available online: https://backend.orbit.dtu.dk/ws/portalfiles/portal/54035355/rapport_m_ltidsvaner2005_2008_4_19_ r_jan.pdf (accessed on 21 January 2021).

11. Bowman, S.A.; Gortmaker, S.L.; Ebbeling, C.B.; Pereira, M.A.; Ludwig, D.S. Effects of Fast-Food Consumption on Energy Intake and Diet Quality among Children in a National Household Survey. Pediatrics 2004, 113, 112-118. [CrossRef] [PubMed]

12. Prentice, A.M.; Jebb, S.A. Fast Foods, Energy Density and Obesity: A Possible Mechanistic Link. Obes. Rev. 2003, 4, 187-194. [CrossRef] [PubMed]

13. WHO/FAO. Diet, Nutrition and the Prevention of Chronic Diseases; World Health Organization: Geneva, Switzerland, 2003.

14. Yngve, A.; Wolf, A.; Poortvliet, E.; Elmadfa, I.; Brug, J.; Ehrenblad, B.; Franchini, B.; Haraldsdóttir, J.; Krølner, R.; Maes, L.; et al. Fruit and Vegetable Intake in a Sample of 11-Year-Old Children in 9 European Countries: The Pro Children Cross-Sectional Survey. Ann. Nutr. Metab. 2005, 49, 236-245. [CrossRef] [PubMed]

15. Blanchette, L.; Brug, J. Determinants of Fruit and Vegetable Consumption among 6-12-Year-Old Children and Effective Interventions to Increase Consumption. J. Hum. Nutr. Diet. 2005, 18, 431-443. [CrossRef] [PubMed]

16. Reinaerts, E.B.M.; de Nooijer, J.M.; Candel, M.J.J.M.; de Vries, N.K. Explaining School Children's Fruit and Vegetable Consumption: The Contributions of Availability, Accessibility, Exposure, Parental Consumption and Habit in Addition to Psychosocial Factors. Appetite 2007, 48, 248-258. [CrossRef] [PubMed]

17. Skinner, J.D.; Carruth, B.R.; Bounds, W.; Ziegler, P.J. Children's Food Preferences: A Longitudinal Analysis. J. Am. Diet. Assoc. 2002, 102, 1638-1647. [CrossRef]

18. Birch, L.L. Development of Food Preferences. Annu. Rev. Nutr. 1999, 19, 41-62. [CrossRef] 
19. Zeinstra, G.G.; Koelen, M.A.; Kok, F.J.; de Graaf, C. Cognitive Development and Children's Perceptions of Fruit and Vegetables; a Qualitative Study. Int. J. Behav. Nutr. Phys. Act. 2007, 4, 30. [CrossRef]

20. Nicklaus, S.; Boggio, V.; Chabanet, C.; Issanchou, S. A Prospective Study of Food Preferences in Childhood. Food Qual. Prefer. 2004, 15, 805-818. [CrossRef]

21. Mikkilä, V.; Räsänen, L.; Raitakari, O.T.; Pietinen, P.; Viikari, J. Consistent Dietary Patterns Identified from Childhood to Adulthood: The Cardiovascular Risk in Young Finns Study. Br. J. Nutr. 2005, 93, 923-931. [CrossRef] [PubMed]

22. te Velde, S.J.; Twisk, J.W.R.; Brug, J. Tracking of Fruit and Vegetable Consumption from Adolescence into Adulthood and Its Longitudinal Association with Overweight. Br. J. Nutr. 2007, 98, 431-438. [CrossRef] [PubMed]

23. Kaikkonen, J.E.; Mikkilä, V.; Raitakari, O.T. Role of Childhood Food Patterns on Adult Cardiovascular Disease Risk. Curr. Atheroscler. Rep. 2014, 16, 1-15. [CrossRef] [PubMed]

24. Ambrosini, G.L.; Emmett, P.M.; Northstone, K.; Jebb, S.A. Tracking a Dietary Pattern Associated with Increased Adiposity in Childhood and Adolescence. Obesity 2014, 22, 458-465. [CrossRef] [PubMed]

25. Havermans, R.C. Increasing Children's Liking and Intake of Vegetables through Experiential Learning. In Bioactive Foods in Promoting Health; Academic Press: Cambridge, MA, USA, 2009; pp. 273-283.

26. Cooke, L. The Importance of Exposure for Healthy Eating in Childhood: A Review. J. Hum. Nutr. Diet. 2007, $20,294-301$. [CrossRef] [PubMed]

27. Lakkakula, A.; Geaghan, J.; Zanovec, M.; Pierce, S.; Tuuri, G. Repeated Taste Exposure Increases Liking for Vegetables by Low-Income Elementary School Children. Appetite 2010, 55, 226-231. [CrossRef]

28. Anzman-Frasca, S.; Savage, J.S.; Marini, M.E.; Fisher, J.O.; Birch, L.L. Repeated Exposure and Associative Conditioning Promote Preschool Children's Liking of Vegetables. Appetite 2012, 58, 543-553. [CrossRef]

29. Zeinstra, G.G.; Vrijhof, M.; Kremer, S. Is Repeated Exposure the Holy Grail for Increasing Children's Vegetable Intake? Lessons Learned from a Dutch Childcare Intervention Using Various Vegetable Preparations. Appetite 2018, 121, 316-325. [CrossRef]

30. Nekitsing, C.; Blundell-Birtill, P.; Cockroft, J.E.; Hetherington, M.M. Systematic Review and Meta-Analysis of Strategies to Increase Vegetable Consumption in Preschool Children Aged 2-5 Years. Appetite 2018, 127, 138-154. [CrossRef]

31. Hausner, H.; Olsen, A.; Møller, P. Mere Exposure and Flavour-Flavour Learning Increase 2-3year-Old Children's Acceptance of a Novel Vegetable. Appetite 2012, 58, 1152-1159. [CrossRef] [PubMed]

32. Remy, E.; Issanchou, S.; Chabanet, C.; Nicklaus, S. Repeated Exposure of Infants at Complementary Feeding to a Vegetable Purée Increases Acceptance as Effectively as Flavor-Flavor Learning and More Effectively Than Flavor-Nutrient Learning. J. Nutr. 2013, 143, 1194-1200. [CrossRef]

33. Wardle, J.; Herrera, M.-L.; Cooke, L.; Gibson, E.L. Modifying Children's Food Preferences: The Effects of Exposure and Reward on Acceptance of an Unfamiliar Vegetable. Eur. J. Clin. Nutr. 2003, 57, 341-348. [CrossRef] [PubMed]

34. Mela, D.J. Why Do We like What We Like? J. Sci. Food Agric. 2001, 81, 10-16. [CrossRef]

35. Feeney, E.L.; O’Brien, S.A.; Scannell, A.G.M.; Markey, A.; Gibney, E.R. Genetic and Environmental Influences on Liking and Reported Intakes of Vegetables in Irish Children. Food Qual. Prefer. 2014, 32, 253-263. [CrossRef]

36. Nicklaus, S. The Role of Food Experiences during Early Childhood in Food Pleasure Learning. Appetite 2016, 104, 3-9. [CrossRef]

37. Szczesniak, A.S. Texture Is a Sensory Property. Food Qual. Prefer. 2002, 13, 215-225. [CrossRef]

38. Sandvik, P.; Laureati, M.; Jilani, H.; Methven, L.; Sandell, M.; Hörmann-Wallner, M.; da Quinta, N.; Zeinstra, G.G.; Almli, V.L. Yuck, This Biscuit Looks Lumpy! Neophobic Levels and Cultural Differences Drive Children's Check-All-That-Apply (CATA) Descriptions and Preferences for High-Fibre Biscuits. Foods 2020, 10, 21. [CrossRef]

39. Birch, L.L. Development of Food Acceptance Patterns in the First Years of Life. Proc. Nutr. Soc. 1998, 57, 617-624. [CrossRef]

40. Falciglia, G.A.; Couch, S.C.; Gribble, L.S.; Pabst, S.M.; Frank, R. Food Neophobia in Childhood Affects Dietary Variety. J. Am. Diet. Assoc. 2000, 100, 1474-1481. [CrossRef]

41. Carruth, B.R.; Skinner, J.; Houck, K.; Moran, J.; Coletta, F.; Ott, D. The Phenomenon of “Picky Eater": A Behavioral Marker in Eating Patterns of Toddlers. J. Am. Coll. Nutr. 1998, 17, 180-186. [CrossRef] [PubMed]

42. Cooke, L.; Wardle, J.; Gibson, E.L. Relationship between Parental Report of Food Neophobia and Everyday Food Consumption in 2-6-Year-Old Children. Appetite 2003, 41, 205-206. [CrossRef]

43. Cooke, L.; Carnell, S.; Wardle, J. Food Neophobia and Mealtime Food Consumption in 4-5 Year Old Children. Int. J. Behav. Nutr. Phys. Act. 2006, 3, 14. [CrossRef] [PubMed]

44. Cooke, L.J.; Wardle, J.; Gibson, E.; Sapochnik, M.; Sheiham, A.; Lawson, M. Demographic, Familial and Trait Predictors of Fruit and Vegetable Consumption by Pre-School Children. Public Health Nutr. 2004, 7, 295-302. [CrossRef] [PubMed]

45. Galloway, A.T.; Lee, Y.; Birch, L.L. Predictors and Consequences of Food Neophobia and Pickiness in Young Girls. J. Am. Diet. Assoc. 2003, 103, 692-698. [CrossRef] [PubMed]

46. Russell, C.G.; Worsley, A. A Population-Based Study of Preschoolers' Food Neophobia and Its Associations with Food Preferences. J. Nutr. Educ. Behav. 2008, 40, 11-19. [CrossRef] [PubMed]

47. Siegrist, M.; Hartmann, C.; Keller, C. Antecedents of Food Neophobia and Its Association with Eating Behavior and Food Choices. Food Qual. Prefer. 2013, 30, 293-298. [CrossRef]

48. Taylor, C.M.; Wernimont, S.M.; Northstone, K.; Emmett, P.M. Picky/Fussy Eating in Children: Review of Definitions, Assessment, Prevalence and Dietary Intakes. Appetite 2015, 95, 349-359. [CrossRef] [PubMed] 
49. Haszard, J.J.; Skidmore, P.M.L.; Williams, S.M.; Taylor, R.W. Associations between Parental Feeding Practices, Problem Food Behaviours and Dietary Intake in New Zealand Overweight Children Aged 4-8 Years. Public Health Nutr. 2015, 18, 1036-1043. [CrossRef] [PubMed]

50. Galloway, A.T.; Fiorito, L.; Lee, Y.; Birch, L.L. Parental Pressure, Dietary Patterns, and Weight Status among Girls Who Are ‘Picky Eaters'. J. Am. Diet. Assoc. 2005, 105, 541-548. [CrossRef]

51. Dubois, L.; Farmer, A.P.; Girard, M.; Peterson, K. Preschool Children's Eating Behaviours Are Related to Dietary Adequacy and Body Weight. Eur. J. Clin. Nutr. 2007, 61, 846-855. [CrossRef] [PubMed]

52. Tharner, A.; Jansen, P.W.; Kiefte-de Jong, J.C.; Moll, H.A.; van der Ende, J.; Jaddoe, V.W.V.; Hofman, A.; Tiemeier, H.; Franco, O.H. Toward an Operative Diagnosis of Fussy/Picky Eating: A Latent Profile Approach in a Population-Based Cohort. Int. J. Behav. Nutr. Phys. Act. 2014, 11, 14. [CrossRef]

53. Howard, A.J.; Mallan, K.M.; Byrne, R.; Magarey, A.; Daniels, L.A. Toddlers' Food Preferences. The Impact of Novel Food Exposure, Maternal Preferences and Food Neophobia. Appetite 2012, 59, 818-825. [CrossRef]

54. Evans, C.E.L.; Hutchinson, J.; Christian, M.S.; Hancock, N.; Cade, J.E. Measures of Low Food Variety and Poor Dietary Quality in a Cross-Sectional Study of London School Children. Eur. J. Clin. Nutr. 2018, 72, 1497-1505. [CrossRef] [PubMed]

55. Taylor, C.M.; Northstone, K.; Wernimont, S.M.; Emmett, P.M. Macro- and Micronutrient Intakes in Picky Eaters: A Cause for Concern? Am. J. Clin. Nutr. 2016, 104, 1647-1656. [CrossRef] [PubMed]

56. Raudenbush, B.; Capiola, A. Physiological Responses of Food Neophobics and Food Neophilics to Food and Non-Food Stimuli. Appetite 2012, 58, 1106-1108. [CrossRef] [PubMed]

57. Kral, T.V.E. Food Neophobia and Its Association with Diet Quality and Weight Status in Children. In Food Neophobia: Behavioral and Biological Influences; Elsevier: Amsterdam, The Netherlands, 2018; pp. 287-303.

58. Perry, R.A.; Mallan, K.M.; Koo, J.; Mauch, C.E.; Daniels, L.A.; Magarey, A.M. Food Neophobia and Its Association with Diet Quality and Weight in Children Aged 24 Months: A Cross Sectional Study. Int. J. Behav. Nutr. Phys. Act. 2015, 12, 13. [CrossRef] [PubMed]

59. Finistrella, V.; Manco, M.; Ferrara, A.; Rustico, C.; Presaghi, F.; Morino, G. Cross-Sectional Exploration of Maternal Reports of Food Neophobia and Pickiness in Preschooler-Mother Dyads. J. Am. Coll. Nutr. 2012, 31, 152-159. [CrossRef] [PubMed]

60. Kaar, J.L.; Shapiro, A.L.B.; Fell, D.M.; Johnson, S.L. Parental Feeding Practices, Food Neophobia, and Child Food Preferences: What Combination of Factors Results in Children Eating a Variety of Foods? Food Qual. Prefer. 2016, 50, 57-64. [CrossRef]

61. Gregory, J.E.; Paxton, S.J.; Brozovic, A.M. Maternal Feeding Practices, Child Eating Behaviour and Body Mass Index in PreschoolAged Children: A Prospective Analysis. Int. J. Behav. Nutr. Phys. Act. 2010, 7, 1-10. [CrossRef] [PubMed]

62. Smith, A.D.; Herle, M.; Fildes, A.; Cooke, L.; Steinsbekk, S.; Llewellyn, C.H. Food Fussiness and Food Neophobia Share a Common Etiology in Early Childhood. J. Child Psychol. Psychiatry 2017, 58, 189-196. [CrossRef]

63. Nicklaus, S.; Monnery-Patris, S. Food Neophobia in Children and Its Relationships with Parental Feeding Practices/Style. In Food Neophobia: Behavioral and Biological Influences; Elsevier: Amsterdam, The Netherlands, 2018; pp. 255-286.

64. Moding, K.J.; Stifter, C.A. Temperamental Approach/Withdrawal and Food Neophobia in Early Childhood: Concurrent and Longitudinal Associations. Appetite 2016, 107, 654-662. [CrossRef]

65. Rothbart, M.K.; Ahadi, S.A.; Hershey, K.L.; Fisher, P. Investigations of Temperament at Three to Seven Years: The Children's Behavior Questionnaire. Child Dev. 2003, 72, 1394-1408. [CrossRef]

66. Rigal, N.; Rubio, B.; Monnery-Patris, S. Is Harsh Caregiving Effective in Toddlers with Low Inhibitory Control? An Experimental Study in the Food Domain. Infant Behav. Dev. 2016, 43, 5-12. [CrossRef]

67. Zajonc, R.B. Mere Exposure: A Gateway to the Subliminal. Curr. Dir. Psychol. Sci. 2001, 10, 224-228. [CrossRef]

68. Laureati, M.; Bergamaschi, V.; Pagliarini, E. School-Based Intervention with Children. Peer-Modeling, Reward and Repeated Exposure Reduce Food Neophobia and Increase Liking of Fruits and Vegetables. Appetite 2014, 83, 26-32. [CrossRef] [PubMed]

69. Kutbi, H.A.; Alhatmi, A.A.; Alsulami, M.H.; Alghamdi, S.S.; Albagar, S.M.; Mumena, W.A.; Mosli, R.H. Food Neophobia and Pickiness among Children and Associations with Socioenvironmental and Cognitive Factors. Appetite 2019, 142, 104373. [CrossRef] [PubMed]

70. Zajonc, R. Attitudinal Effects of Mere Exposure. J. Pers. Soc. Psychol. 1968, 9, 1-27. [CrossRef]

71. Mura Paroche, M.; Caton, S.J.; Vereijken, C.M.J.L.; Weenen, H.; Houston-Price, C. How Infants and Young Children Learn About Food: A Systematic Review. Front. Psychol. 2017, 8, 1046. [CrossRef] [PubMed]

72. Maier, A.; Chabanet, C.; Schaal, B.; Issanchou, S.; Leathwood, P. Effects of Repeated Exposure on Acceptance of Initially Disliked Vegetables in 7-Month Old Infants. Food Qual. Prefer. 2007, 18, 1023-1032. [CrossRef]

73. Wadhera, D.; Capaldi Phillips, E.D.; Wilkie, L.M. Teaching Children to like and Eat Vegetables. Appetite 2015, 93, 75-84. [CrossRef] [PubMed]

74. Osborne, C.L.; Forestell, C.A. Increasing Children's Consumption of Fruit and Vegetables: Does the Type of Exposure Matter? Physiol. Behav. 2012, 106, 362-368. [CrossRef] [PubMed]

75. Ahern, S.M.; Caton, S.J.; Bouhlal, S.; Hausner, H.; Olsen, A.; Nicklaus, S.; Møller, P.; Hetherington, M.M. Eating a Rainbow. Introducing Vegetables in the First Years of Life in 3 European Countries. Appetite 2013, 71, 48-56. [CrossRef]

76. Grimm, K.A.; Kim, S.A.; Yaroch, A.L.; Scanlon, K.S. Fruit and Vegetable Intake During Infancy and Early Childhood. Pediatrics 2014, 134, S63-S69. [CrossRef] 
77. Gregory, J.E.; Paxton, S.J.; Brozovic, A.M. Maternal Feeding Practices Predict Fruit and Vegetable Consumption in Young Children. Results of a 12-Month Longitudinal Study. Appetite 2011, 57, 167-172. [CrossRef]

78. Bornstein, R.F.; Kale, A.R.; Cornell, K.R. Boredom as a Limiting Condition on the Mere Exposure Effect. J. Pers. Soc. Psychol. 1990, 58, 791-800. [CrossRef]

79. Köster, E.P.; Mojet, J. Familiarity, Monotony, or Variety: The Role of Flavor Complexity in Food Intake. In Flavor: From Food to Behaviors, Wellbeing and Health; Elsevier: Amsterdam, The Netherlands, 2016; pp. 277-291.

80. Keller, K.L. The Use of Repeated Exposure and Associative Conditioning to Increase Vegetable Acceptance in Children: Explaining the Variability Across Studies. J. Acad. Nutr. Diet. 2014, 114, 1169-1173. [CrossRef] [PubMed]

81. Ahern, S.M.; Caton, S.J.; Blundell, P.; Hetherington, M.M. The Root of the Problem: Increasing Root Vegetable Intake in Preschool Children by Repeated Exposure and Flavour Flavour Learning. Appetite 2014, 80, 154-160. [CrossRef] [PubMed]

82. Birch, L.L.; Gunder, L.; Grimm-Thomas, K.; Laing, D.G. Infants' Consumption of a New Food Enhances Acceptance of Similar Foods. Appetite 1998, 30, 283-295. [CrossRef] [PubMed]

83. Shutts, K.; Kinzler, K.D.; DeJesus, J.M. Understanding Infants' and Children's Social Learning about Foods: Previous Research and New Prospects. Dev. Psychol. 2013, 49, 419-425. [CrossRef] [PubMed]

84. Salvy, S.-J.; Pliner, P. Social Influences on Eating in Children and Adults. In Obesity Prevention; Elsevier Inc.: Amsterdam, The Netherlands, 2010; pp. 617-627.

85. Estay, K.; Pan, S.; Zhong, F.; Capitaine, C.; Guinard, J.-X. A Cross-Cultural Analysis of Children's Vegetable Preferences. Appetite 2019, 142, 104346. [CrossRef]

86. Saxholt, E.; Christensen, A.T.; Møller, A.; Hartkopp, H.B.; Hess Ygil, K.; Hels, O.H. Fødevarerdatabanken Version 7.01; Afdeling for Ernæring, Fødevareinstituttet DTU: Søborg, Denmark, 2009.

87. Christensen, L.P.; Edelenbos, M.; Kreutzmann, S. Fruits and Vegetables of Moderate Climate. In Flavours Fragrances; Springer: Berlin/Heidelberg, Germany, 2007; pp. 169-172.

88. McGee, H. A Survey of Common Vegetables. In McGee on Food and Cooking, an Encyclopedia of Kitchen Science, History and Culture; Hodder and Stoughton: London, UK, 2004; pp. 309-310, 320-324, 328.

89. Olsen, A.; Ritz, C.; Kraaij, L.W.; Møller, P. Children's Liking and Intake of Vegetables: A School-Based Intervention Study. Food Qual. Prefer. 2012, 23, 90-98. [CrossRef]

90. Olsen, A.; Ritz, C.; Kramer, L.; Møller, P. Serving Styles of Raw Snack Vegetables. What Do Children Want? Appetite 2012, 59, 556-562. [CrossRef] [PubMed]

91. Popper, R.; Kroll, J.J. Consumer Testing of Food Products Using Children. In Developing Children's Food Products; Elsevier: Amsterdam, The Netherlands, 2011; pp. 163-187.

92. Holley, C.E.; Haycraft, E.; Farrow, C. 'Why Don't You Try It Again?' A Comparison of Parent Led, Home Based Interventions Aimed at Increasing Children's Consumption of a Disliked Vegetable. Appetite 2015, 87, 215-222. [CrossRef] [PubMed]

93. Maxwell, A.E.; Castillo, L.; Arce, A.A.; De Anda, T.; Martins, D.; McCarthy, W.J. Eating Veggies Is Fun! An Implementation Pilot Study in Partnership with a YMCA in South Los Angeles. Prev. Chronic Dis. 2018, 15, E132. [CrossRef] [PubMed]

94. Zeinstra, G.G.; Renes, R.J.; Koelen, M.A.; Kok, F.J.; de Graaf, C. Offering Choice and Its Effect on Dutch Children's Liking and Consumption of Vegetables: A Randomized Controlled Trial. Am. J. Clin. Nutr. 2010, 91, 349-356. [CrossRef] [PubMed]

95. Wardle, J.; Guthrie, C.A.; Sanderson, S.; Rapoport, L. Development of the Children's Eating Behaviour Questionnaire. J. Child Psychol. Psychiatry 2001, 42, 963-970. [CrossRef] [PubMed]

96. Musher-Eizenman, D.; Holub, S. Comprehensive Feeding Practices Questionnaire: Validation of a New Measure of Parental Feeding Practices. J. Pediatr. Psychol. 2007, 32, 960-972. [CrossRef]

97. Pliner, P. Development of Measures of Food Neophobia in Children. Appetite 1994, 23, 147-163. [CrossRef] [PubMed]

98. Jose, P.; Bates, D.; DebRoy, S.; Sarkar, D.; R Core Team. \{nlme\}: Linear and Nonlinear Mixed Effects Models; Springer: New York, NY, USA, 2018.

99. Hothorn, T.; Bretz, F.; Westfall, P. Simultaneous Inference in General Parametric Models. Biometrical J. 2008, 50, 346-363. [CrossRef]

100. De Wild, V.W.T.; de Graaf, C.; Jager, G. Effectiveness of Flavour Nutrient Learning and Mere Exposure as Mechanisms to Increase Toddler's Intake and Preference for Green Vegetables. Appetite 2013, 64, 89-96. [CrossRef] [PubMed]

101. Caton, S.J.; Ahern, S.M.; Remy, E.; Nicklaus, S.; Blundell, P.; Hetherington, M.M. Repetition Counts: Repeated Exposure Increases Intake of a Novel Vegetable in UK Pre-School Children Compared to Flavour-Flavour and Flavour-Nutrient Learning. Br. J. Nutr. 2013, 109, 2089-2097. [CrossRef]

102. Bouhlal, S.; Issanchou, S.; Chabanet, C.; Nicklaus, S. 'Just a Pinch of Salt'. An Experimental Comparison of the Effect of Repeated Exposure and Flavor-Flavor Learning with Salt or Spice on Vegetable Acceptance in Toddlers. Appetite 2014, 83, 209-217. [CrossRef]

103. de Wild, V.; de Graaf, C.; Jager, G. Efficacy of Repeated Exposure and Flavour-Flavour Learning as Mechanisms to Increase Preschooler's Vegetable Intake and Acceptance. Pediatr. Obes. 2015, 10, 205-212. [CrossRef]

104. de Wild, V.W.T.; de Graaf, C.; Jager, G. Use of Different Vegetable Products to Increase Preschool-Aged Children's Preference for and Intake of a Target Vegetable: A Randomized Controlled Trial. J. Acad. Nutr. Diet. 2017, 117, 859-866. [CrossRef] [PubMed]

105. Nederkoorn, C.; Theißen, J.; Tummers, M.; Roefs, A. Taste the Feeling or Feel the Tasting: Tactile Exposure to Food Texture Promotes Food Acceptance. Appetite 2018, 120, 297-301. [CrossRef] [PubMed] 
106. Nekitsing, C.; Blundell-Birtill, P.; Cockroft, J.E.; Hetherington, M.M. Taste Exposure Increases Intake and Nutrition Education Increases Willingness to Try an Unfamiliar Vegetable in Preschool Children: A Cluster Randomized Trial. J. Acad. Nutr. Diet. 2019, 119, 2004-2013. [CrossRef]

107. Ahern, S.M.; Caton, S.J.; Blundell-Birtill, P.; Hetherington, M.M. The Effects of Repeated Exposure and Variety on Vegetable Intake in Pre-School Children. Appetite 2019, 132, 37-43. [CrossRef]

108. Houston-Price, C.; Owen, L.H.; Kennedy, O.B.; Hill, C. Parents' Experiences of Introducing Toddlers to Fruits and Vegetables through Repeated Exposure, with and without Prior Visual Familiarization to Foods: Evidence from Daily Diaries. Food Qual. Prefer. 2019, 71, 291-300. [CrossRef]

109. Mohd Nor, N.D.; Houston-Price, C.; Harvey, K.; Methven, L. The Effects of Taste Sensitivity and Repeated Taste Exposure on Children's Intake and Liking of Turnip (Brassica Rapa Subsp. Rapa); a Bitter Brassica Vegetable. Appetite 2021, $157,104991$. [CrossRef] [PubMed]

110. Zandstra, E.H.; de Graaf, C.; van Trijp, H.C.M. Effects of Variety and Repeated In-Home Consumption on Product Acceptance. Appetite 2000, 35, 113-119. [CrossRef]

111. Birch, L.L.; McPhee, L.; Shoba, B.C.; Pirok, E.; Steinberg, L. What Kind of Exposure Reduces Children's Food Neophobia? Looking vs. Tasting. Appetite 1987, 9, 171-178. [CrossRef]

112. Loewen, R.; Pliner, P. Effects of Prior Exposure to Palatable and Unpalatable Novel Foods on Children's Willingness to Taste Other Novel Foods. Appetite 1999, 32, 351-366. [CrossRef] [PubMed]

113. Hetherington, M.M.; Schwartz, C.; Madrelle, J.; Croden, F.; Nekitsing, C.; Vereijken, C.M.J.L.; Weenen, H. A Step-by-Step Introduction to Vegetables at the Beginning of Complementary Feeding. The Effects of Early and Repeated Exposure. Appetite 2015, 84, 280-290. [CrossRef] [PubMed]

114. Wyse, R.; Wolfenden, L.; Bisquera, A. Characteristics of the Home Food Environment That Mediate Immediate and Sustained Increases in Child Fruit and Vegetable Consumption: Mediation Analysis from the Healthy Habits Cluster Randomised Controlled Trial. Int. J. Behav. Nutr. Phys. Act. 2015, 12, 118. [CrossRef] [PubMed] 